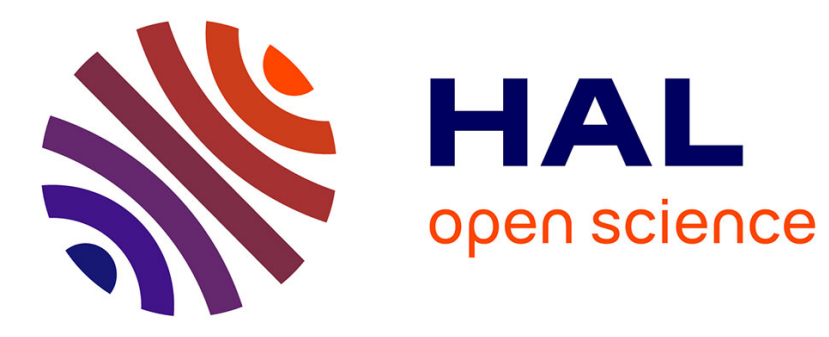

\title{
On the definition of externality as a missing market
}

Nathalie Berta

\section{To cite this version:}

Nathalie Berta. On the definition of externality as a missing market. European Journal of the History of Economic Thought, 2017, 24 (2), pp.287-318. 10.1080/09672567.2016.1169304 . hal-02095696

\section{HAL Id: hal-02095696 https://hal.univ-reims.fr/hal-02095696}

Submitted on 10 Apr 2019

HAL is a multi-disciplinary open access archive for the deposit and dissemination of scientific research documents, whether they are published or not. The documents may come from teaching and research institutions in France or abroad, or from public or private research centers.
L'archive ouverte pluridisciplinaire HAL, est destinée au dépôt et à la diffusion de documents scientifiques de niveau recherche, publiés ou non, émanant des établissements d'enseignement et de recherche français ou étrangers, des laboratoires publics ou privés. 


\title{
On the definition of externality as a missing market
}

\author{
Nathalie Berta ${ }^{1}$
}

[This is an Accepted Manuscript of an article published by Taylor \& Francis in the European Journal of History of Economic Thought, 24(2), 2017, available online:

http://www.tandfonline.com/10.1080/09672567.2016.1169304].

\section{Introduction}

From a conceptual point of view, externality seen as a missing market depends on the way economic theory draws the frontiers between market and non-market activities. It thus depends on the definition of market. From a normative point of view, externality seen as a market failure may call for its internalisation. It is one of the main justifications for public intervention and for the creation of markets where they do not exist. But despite these important stakes and the increasing role of this concept in economic theory, externality seems to elude any attempt at rigorous and consensual definition. The problem of definition has emerged with the concept itself in the 1950s, when it became emancipated from its forerunner, the Marshallian concept of external economies. Several authors successively tried to clarify the notion (Meade 1952, Scitovsky 1954, Bator 1958, Buchanan and Stubblebine 1962, Arrow 1969). But a few years later, the same lack of rigorous definition was still emphasised: "Externality is in some ways, a straightforward concept: yet, in others, it is extraordinarily elusive. We know how to take it into account in our analysis, and we are aware of many of its implications, but, despite a number of illuminating attempts to define the notion, one is left with the feeling that we have not captured all its ramifications." (Baumol and Oates 1975, 14) Furthermore, since this period of intense debate on externality, the specialisation of economic theory in distinct fields has generated various meanings and uses

\footnotetext{
${ }^{1}$ REGARDS, Reims University, nathalie.berta@univ-reims.fr. I am grateful to Elodie Bertrand, André Lapidus and Michel De Vroey for their invaluable advices.
} 
of the concept. Papandreou (1994) has presented a rich history of the concept - relating each field of economic theory to its own meaning of externality. ${ }^{2}$

It is not my intention to provide a typology of the various meanings of externality, or to present a broad history of the concept. This study is circumscribed by time and focus strictly on the approach falling within the general competitive equilibrium framework, more precisely within its axiomatic form, the Arrow-Debreu model, developed in the 1950s. ${ }^{3}$ Within this framework, the definition of externality is rooted in Arrow's (1969) pioneering work: it is a type of missing market and encompasses the unpriced effects of one agent's activity on the welfare of another agent. As a consequence, it upsets the assumption of the complete system of markets that the first theorem of welfare economics requires, producing a Paretian sub-optimality. From a mathematical point of view, the formalisation of an externality is achieved by introducing a direct interdependence between utility or production functions.

The interest of this study of the definition of externality coming from the ArrowDebreu framework is twofold. First, although some studies provide a history of the concept related to specific authors - see Medema (2011A, 2011B) on Coase, or Marciano (2013) on Buchanan - it has never been done, to our knowledge, in the general equilibrium theory. Second, the study raises analytical issues: Indeed, even in such a rigorous analytical framework, the definition of externality as a missing market, despite its apparent simplicity, allows some ambiguities to persist. As witnessed by some authors' positions in the 1970s (Mishan 1971, Baumol and Oates 1975, Heller and Starrett 1976, and Laffont 1988), this Arrovian definition does not highlight two features usually associated with the traditional meaning of externalities as side effects: whether or not it is an exogenous effect and whether or not it is an unintended effect. I argue that both these ambiguities raise, although differently, the more general issue of the dilution of the concept of externality within the larger notion of individual interdependences. Finally, beyond the conceptual importance of clarifying the definition of externality as a missing market, this issue has a strong normative content since externalities call for internalisation and public intervention. So, giving a strict definition of

\footnotetext{
${ }^{2}$ See also, for a less detailed discussion of the concept during the 1950s and 1960s, Mishan (1971), Baumol and Oates (1975), Laffont (1975), and Cornes and Sandler (1986). Papandreou's (1994) work is the only attempt to draw an exhaustive portrait of the various definitions of externality from a history of economic thought perspective, relating each definition to its specific context.

3 The Arrow-Debreu framework, also called the Arrow-Debreu-Mckenzie framework, emerged with the first existence proofs of Arrow, Debreu, McKenzie and Gale. Debreu (1959) gave it its most elegant and definitive form.
} 
externality amounts, implicitly, to drawing the frontier of legitimate internalisation and to limiting the scope of the required economic policy.

Since this study is limited to the Arrow-Debreu framework, it is restricted to an ideal world without transaction costs (for a discussion of the introduction of transaction costs in Arrow's and Coase's internalisation of externalities, see e.g., Berta and Bertrand 2014). It does not concern itself with the use of externalities in some important theoretical fields, especially in macroeconomics, the institutional approach and the theory of property rights. ${ }^{4}$ Moreover, this study focuses on the conceptual problems of definition and does not discuss traditional internalisation modes and their respective relevance.

Sections II and III are dedicated to the definition of externality as a missing market or, by metonymy, as an unpriced effect. These sections are mainly based on Arrow's (1969) work. Section II first presents the place of Arrow (1969) in the literature on externalities in the 1960s. Section III then discusses Arrow's definitions of externality and market failure which have become seminal.

Sections IV and V, respectively, focus on the uncontrollable and unintended features of externality in the general equilibrium theory. First, in a competitive framework where every decision is supposed to be based on parametrical prices, an externality - as an effect that escapes this system of prices - is outside the recipient's control, to such an extent that the recipient could be called an 'externality taker' in the same way that he is a price taker. However, this uncontrollable or exogenous feature of an externality, embedded in the basic formalisation of the competitive framework, is questioned by the ambiguous status of barter. As barter produces a direct interdependence between agents (a utility interdependence), it is regarded as an externality by several authors, who also belong to the general equilibrium approach (Heller and Starrett 1976, Laffont 1988). This assimilation confuses the frontier between externality and simple economic interdependence since barter is a kind of market even though not a competitive one - and remains a chosen and controlled decision (Section IV).

Second, the definition of externality as a missing market does not specify whether or not externalities are unintended or involuntary activities. In the general equilibrium theory,

\footnotetext{
${ }^{4}$ As stressed by Lagueux (2010), the definition of externality as a missing market is a residual concept, depending on what is precisely regarded beyond the missing market. Externality can be associated with missing property rights, with "the divorce of scarcity from effective ownership" (Ellis and Fellner 1943, cited by Lagueux 2010, 962). But this is not the focus adopted in the general equilibrium framework since the latter does not question the origin of missing markets and, for example, the lack of property rights. This is why the property rights theory is beyond the scope of this paper. I will return to this point later (Section III.2).
} 
the formalisation of an externality as an interdependence between functions of utility or production can receive a very broad interpretation. It allows the concept to include all kinds of unpriced individual interactions. This is why some authors (Mishan 1965, 1969, 1971, Baumol and Oates 1975) try to circumscribe the concept and to limit its meaning to very specific phenomena. More precisely, they try to limit the concept to unintended or accidental side effects, emphasising the intuitive or traditional meaning associated with externality (Section V). There is thus a tension between, on the one hand, a formal and broad approach of externality - within which missing markets can encompass, nearly all kinds of unpriced interdependences - and, on the other hand, a more restrictive approach, an essentialist or 'phenomenological' definition (Papandreou 1994). ${ }^{5}$

Both ambiguities raise the issue of the relation between the basic formalisation of externalities (a mathematical dependence of individual objective functions) and its economic meaning (an unpriced effect or a missing market). Finally, both ambiguities raise the issue of the dilution of externality in the larger notion of individual interaction and question its strong normative content.

\section{The place of Arrow (1969) in the literature on externalities}

In the general equilibrium theory, the definition of externality comes from the analytical framework of the Arrow-Debreu model, whose axiomatisation has been achieved since Debreu's (1959) seminal work. Externality encompasses the unpriced effects or missing markets that invalidate the assumption of a complete system of markets - an assumption that, according to the first fundamental theorem of welfare economics, is required for Pareto optimality. This definition of externality as a missing market is rooted in Arrow (1969) - the only founder of the general equilibrium theory who clearly addresses this issue. This section first discusses Arrow's (1969) place in the literature on externalities in the 1960s (II.1), in the general equilibrium theory (II.2), and finally in Arrow’s own work (II.3).

\section{II.1 The place of Arrow (1969) in the literature on externality}

In the middle of the $20^{\text {th }}$ century externalities had not yet received a clear and wellestablished meaning. Since Viner's (1931) contribution, the term usually refers to effects that

\footnotetext{
${ }^{5}$ This expression of a 'phenomenological' approach to qualify authors who try to limit externalities to special phenomena, such as unintended effects, comes from Papandreou (1994).
} 
produce deviations from Pareto optimality - called technological externalities - and thus excludes pecuniary externalities. But in the 1950s and 1960s, during "this period of running discussion on the theory of externality" (Baumol 1965, 24), several papers (mainly Bator 1958, Baumol 1965, Buchanan and Stubblebine 1962, Meade 1952, Scitovsky 1954) 6 successively tried to clarify this concept by providing their own distinctions and typologies.

Meade's famous "unpaid factors" are still rooted in Marshall's concept of external economies or diseconomies ${ }^{7}$ and thus in the field of production. But, as emphasized by Laffont (1975), Meade is the first to clearly focus on technological externalities and his paper marks the beginning of the modern theory of externality. With Scitovsky's (1954) and Bator's (1958) contributions, the concept of externality progressively became emancipated from its famous Marshallian forerunner, and started to encompass 'unpriced' or 'direct' interactions in all economic activities. Scitovsky (1954) underlined that, in the theory of competitive equilibrium, externality refers to unpriced direct interactions - between producers, between consumers or between consumers and producers. This definition is broader than Meade's unpaid factors, which belong only to Scitovsky's first kind of interactions. ${ }^{8}$ A few years later, Bator (1958) gave a wider definition of externalities, which encompasses all the possible causes of market failure and inefficiency: "external economies, indivisibility, nonappropriation, direct interaction, public goods, atmosphere, etc.” (Bator 1958, 356). As stressed by Medema (2014B), Bator was the first person to introduce the term 'externality' in the literature in a previous paper devoted to welfare economics (Bator 1957).

All these authors successively emphasised the fact that despite their predecessors' attempts to clarify the concept, a rigorous definition was not yet available. ${ }^{9}$ And they all

\footnotetext{
${ }^{6}$ Coase (1960) is not mentioned here since his purpose was not to propose a new definition of externality, a term that he did not use in the paper, but rather to focus on the internalisation mode and the role of transaction costs.

${ }^{7}$ Marshall (1890) introduced the concept of external economies in order to explain the decline of an industry's long-term offer price curve, while maintaining the assumption of the firm's increasing marginal costs, i.e. trying to "provide a means for saving the competitive model, of ducking the monopoly problem" (Bator 1958). This Marshallian concept, "one of the most elusive in economic literature" (Scitovsky 1954, 143), generated the 'empty box' controversy between the two wars until Viner (1931) dispelled some misconceptions by introducing a decisive distinction between pecuniary external economies (effects that have prices and do not produce Paretian sub-optimality) and technological external economies. For more details, see Laffont (1975), Mishan (1971), Papandreou (1994).

${ }^{8}$ Scitovsky reaffirmed Viner's distinction between technological and pecuniary externalities. He clarified the former definition as direct interaction and distinguished it from a second definition, coming from the "theory of industrialization of underdeveloped countries". The latter definition is beyond the scope of this study since externality here has a broader meaning and refers to pecuniary external economies. It refers to the problem of allocating savings amongst different kinds of investment and specifically an investment which can no longer be based on its own private profitability.

9 For example, despite Scitovsky's and Bator's attempts, Buchanan and Stubblebine (1962) assert that "externality has been, and is, central to the neo-classical critique of market organization [...]. Despite this
} 
provided their own and more or less restrictive definition. So doing, they tried to clarify, on the one hand, the relationship between externality and market failure - and, thus, suboptimality - and, on the other hand, the connection between externality and individual 'direct' interaction. As later stressed by Baumol and Oates (1975, 15), "ultimately, definitions are a matter of taste and convenience", and each of these earlier contributions attempted to establish what kind of phenomena, of individual interdependences, externalities should or should not encompass. (For theoretical surveys of these attempts at clarifying the concept see Baumol and Oates (1975), Cornes and Sandler (1986), Laffont (1975), Mishan (1971); for a history of these definitions, see Berta (2008), Medema (2014B) or Papandreou (1994)).

Yet at the same time Arrow was writing, that is at the end of the 1960s, there was, at least in the competitive equilibrium theory on which this paper focuses, a consensus that first, externalities only encompass 'unpriced' or non-market interactions - that is, only 'direct' interactions - and second, that they produce sub-optimalities. Although Bator tried to broaden the definition to include all types of market failures, he first stressed:

"In its modern version, the notion of external economies - external economies proper that is: Viner's technological variety - belongs to a more general doctrine of 'direct interaction'. Such interaction [...] consists in interdependences that are external to the price system, hence unaccounted for by market valuations. Analytically, it implies the nonindependence of various preference and production functions." $(1958,358)^{10}$

As a consequence, since "in general equilibrium, direct interdependence is the villain of the piece" (Scitovsky 1954, 144), externality thus produces Paretian sub-optimality. Pecuniary externalities or general equilibrium effects are then usually considered irrelevant, for they are actually internal effects that do not produce any Paretian sub-optimality. ${ }^{11}$

Arrow's work (1969) is part of these successive attempts to clarify the definition of externality. Asserting that "it is time to discuss some of the standard concepts of externality,

\footnotetext{
importance and emphasis, rigorous definitions of the concept itself are not readily available in the literature." (Buchanan and Stubblebine 1962, 371).

${ }^{10}$ This rather consensual definition is also underlined by Buchanan and Stubblebine (1962). While their purpose was to provide a new distinction between Pareto-relevant and Pareto-irrelevant externalities, they acknowledged that 'the term 'externality', as generally used by economists, corresponds only to our definition of Paretorelevant externality" (1962,371), that is, to unpriced and sub-optimal interactions.

${ }^{11}$ See, for example Buchanan and Stubblebine (1962), Meade (1952), Scitovsky (1954). Even in Bator's definition, which is the broadest one, externality as a cause of market failures creates sub-optimality and thus does not encompass any individual interaction.
} 
market failure and public goods generally", he acknowledged that "the clarification of these concepts is a long historical process, not yet concluded" (Arrow 1969, 145). He then mentioned some of these earlier contributions but, unfortunately, it was just in passing and he did not provide any comparison or even any further comment. ${ }^{12}$

\section{II.2 The place of Arrow (1969) in the general equilibrium theory}

Arrow's definition of externality as a missing market and its internalisation by what are now called 'Arrovian markets' (e.g., Boyd and Conley 1997) have become seminal. This is obviously due to the fact that he is the first one to propose an internalisation mode that expands the complete system of markets to include externalities (with parametric personalised prices for externalities, as shown below).

The special place of Arrow (1969) in the general equilibrium theory of externality is also due to the fact that, surprisingly enough, Arrow is the only founding theoretician of general equilibrium who raises this question of the definition of externality in a straightforward manner. Samuelson's famous papers on public expenditures $(1954,1955)$ focus on the definition of public goods and its sub-optimality but do not deal at all with externalities. Later, Samuelson (1958) emphasised the importance of externality: "I don't suppose that anyone, upon reflection, would try to build up a theory of public expenditure without bringing in some kind of externality" (1958, 334). But just after claiming "let's introduce important externalities ('neighborhood' effects etc.) into the consumption sphere" $(1958,334)$, he carries on with a model that explicitly assumes the presence of public goods, like national defence. Actually, the paper still addressed issues related to public goods and Samuelson did not give any definition of externality that seemed to be implicitly associated with public goods. ${ }^{13}$

In the same way, this issue of definition is not addressed by the main founders of the Arrow-Debreu model during the same period, (e.g., Debreu, McKenzie or Hahn). For example, Debreu, in his famous Theory of Value (1959), underlined the importance of the complete system of markets assumption and introduced, at the end of the book, a chapter on contingent markets, which are missing markets, in order to enlarge the complete system of markets. But he did not introduce any chapter devoted to those other missing markets that

\footnotetext{
${ }^{12}$ He mentioned Meade (1952), Scitovsky (1954), Coase (1960), Buchanan and Stubblebine (1962) and Demsetz (1966), but singularly he did not mention Bator (1954).

${ }^{13}$ From a mathematical point of view, the concepts of externality and public goods are closely linked since all public goods can produce externalities (on this issue, see Cornes and Sandler 1986, for example).
} 
make up externalities in the Arrow-Debreu model. Moreover, he did not address this issue in any later work. In fact, during the 1950s and 1960s, the main founders of the general equilibrium theory focused on the construction of the Arrow-Debreu model - on its axiomatisation - and on the two main problems raised by the internal consistency of the model: the existence and the stability of competitive equilibrium.

Rapidly, however, Arrow's internalisation of externalities through the creation of missing markets, of competitive markets for externalities, is taken up by, for example, Starrett (1972) and Laffont (1976). Arrow was a professor at Harvard University between 1968 and 1976. Laffont and Starrett were his students at the beginning of the 1970s and their interest in the topic of externalities in a general equilibrium framework surely came from their professor's influence - although they would provide their own interpretation of the concept (see Section IV below). Laffont (1977) writes the only book devoted to external effects in a general equilibrium framework. ${ }^{14}$ It is mainly based on earlier papers devoted to externalities (Laffont and Laroque 1972, Laffont 1975, 1976). ${ }^{15}$

\section{II.3 The place of Arrow's 1969 contribution in his own work}

Not only is Arrow the only founder of the general equilibrium theory to question the definition of externality, but his 1969 article is also his sole contribution to this issue. Arrow and Hahn (1971) returned, in a small sub-section of their book, to the internalisation of externality by the creation of competitive markets. Later Arrow (1979) focused on a noncooperative game approach to Coase's solution to externality. But these two studies only focused on internalisation modes and never addressed the issue of the definition of externality. Rather surprisingly, none of Arrow's other papers returned to this issue and, in his Nobel lecture (Arrow 1972) a few years later, he did not even mention his 1969 paper. Even in his later contributions that deal with environmental concerns, he never referred to externalities (see e.g., Arrow and Fisher 1974 that focuses on uncertainty in environmental policies and more recently Arrow et al. 1993 that deals with contingent valuation).

Arrow was a very prolific theorist who worked on a great variety of subjects, as witnessed by his collected papers. He contributed to the most important results of the ArrowDebreu model - welfare economics (Arrow 1951) and existence proofs (Arrow and Debreu

\footnotetext{
${ }^{14}$ Another exception is Baumol and Oates's book (1975). They adopt a general equilibrium approach but are concerned with environmental issues. This is why they provide their own definition of externality. I will come back to this point later.

${ }^{15}$ Laffont (1987) has also written the 'externality' entry in the New Palgrave.
} 
1954). But while he was aware of the importance of these theoretical results, he was always trying to achieve more realism. As emphasised by Kornai, "more than one of his studies are extremely abstract analyses. However, to complement the speculative and deductive intellectual work, he reverts repeatedly to the timely and practical questions of everyday life" (Kornai 1979, 201; see also Arrow's own preface to Arrow 1985). ${ }^{16}$ Arrow's twofold interest in high theory and the real world explains why, unlike Debreu for example, he was interested in market failures, which include externalities. This is also why he worked on applied economics and on imperfect competition models (e.g., markets for risk bearing, medical care, information problems, uncertainty, etc.). As stressed by Bliss (1987, p. 303): "Yet there is no doubt that pure general equilibrium is not for Arrow an end in itself. Its interest for him springs from its role as a point of reference for the evaluation of the performance and potential of real world markets". In fact, Arrow's work often focuses on problems generated by missing markets. In his famous paper on medical care (1963), he refers to the problems of the 'non-marketability' of goods and services, to missing markets. In Arrow and Lind (1970) and Arrow and Fisher (1974), he works on uncertainty, stressing again the issue of contingent markets as missing markets. According to him, as we will see below (Section III), externalities are only a special case of missing markets - i.e. all missing markets are not externalities. This is probably why he never refers to externalities in his numerous applied contributions on other missing markets.

\section{Externalities as missing markets}

Arrow (1969) establishes his own definitions of externality and market failure and introduces the formalisation of externality as a utility-interdependence - a formalisation that is now seminal in the general equilibrium framework.

\section{III.1 Arrow's (1969) definitions of market failure and externality ${ }^{17}$}

Arrow (1969) starts by acknowledging the same lack of definition of externality as his predecessors did:

\footnotetext{
${ }^{16}$ See also Berta and Bertrand (2014).

${ }^{17}$ See also Berta and Bertrand (2014) for a comparison of Arrow and Coase on methodology and 'market' internalisation.
} 
"Surprisingly enough, nowhere in the literature does there appear to be a clear general definition of the [public good] concept or the more general one of 'externality'. The accounts given are usually either very general and discursive, difficult to interpret in specific contexts, or else they are rigorous accounts of very special situations.” (Arrow 1969, 133)

One of Arrow's (1969) purposes is to clarify the definition of externality and, more precisely, its relation with increasing returns and with the broader notion of market failure.

\begin{abstract}
"These [increasing returns and market failure] are related to Pareto inefficiency on the one hand and to the existence and optimality of competitive equilibrium on the other; sometimes discussions in the literature do not adequately distinguish these two aspects. Market failure is a more general category than externality and both differ from increasing returns in a basic sense, since market failures in general and externalities in particular are relative to the mode of economic organization, while increasing returns are essentially a technological phenomenon.” (Arrow 1969, 134)
\end{abstract}

Arrow's definitions of market failure and externality are implicitly outlined in his paper - market failures refer to "failures of markets to exist", i.e. to "missing markets" in general (Arrow 1969, 148). Externalities are just a particular case of market failures, i.e. of missing markets. This is why he says that market failures and thus externalities are institutional, relative to the economic organisation, to the non-existence of markets, while increasing returns are neither externalities nor even market failures since he considers that scale returns are technological.

This concept of market failure is more restrictive than Bator's (1958) definition, which Arrow is aware of, although he does not mention it in his 1969 paper. ${ }^{18}$ Bator (1958) considers that every cause of sub-optimality - including increasing returns - is a failure and also an externality. ${ }^{19}$ This broad concept of market failure, which includes all kinds of suboptimality, of imperfections of competition, is usual in the literature. ${ }^{20}$ This is not Arrow's restrictive conception of market failure. His conception is driven by the general equilibrium

\footnotetext{
${ }^{18}$ Surprisingly, Arrow does mention Bator in his famous paper on medical care (1963), for example.

${ }^{19}$ More precisely, Bator gives a typology of externalities as the causes of market failure.

${ }^{20}$ This is the definition given by Bohm (1987) in the New Palgrave, and by Newbery (1990, 212): "market failure means that the existing markets fail to achieve the efficient allocation that the idealized, perfectly competitive markets of the First theorem would ensure". A market failure is a cause of sub-optimality and it includes everything that impedes competitive equilibrium from existing, and thus also convexity problems.
} 
analytical framework and, more precisely, by the kinds of deviations from Pareto optimality that Arrow considers decisive. He separates the two main assumptions required for Pareto optimality: convexity and the complete system of markets. Indeed, according to him, the main problems that upset the two fundamental welfare theorems, "the hypotheses frequently not valid" (Arrow 1969, 135), are 1) the non-convexity problems, since the existence of a competitive equilibrium is no longer guaranteed, and 2) the lack of "universal markets" (ibid. , 135) since a general competitive equilibrium exists but is no longer Pareto optimal. Only the second type of phenomenon, that of missing markets and hence externalities, is considered a market failure, while convexity problems - among which are increasing returns - are not. Thus, market failures seen as missing markets undermine only the first theorem of welfare economics. $^{21}$

It is now usual within the general equilibrium framework to distinguish between market failures and convexity problems or, more precisely, between externality and increasing returns. This is, for example, the position adopted a few years later by Baumol and Oates (1975). According to them, "Bator, who makes no attempt to define the concept of externality very formally, nevertheless proposes to interpret the concept so broadly that it includes most major sources of what he calls "market failures"” $(1975,16)$. But they continue, "one can only object that this broad connotation is not what most writers have in mind when they discuss externalities. The analysis of the increasing-returns problem is ultimately quite different from that of the more conventional externalities that constitute the primary threat to the environment and to the quality of life more generally." (ibid., 16) ${ }^{22}$ They then refer to "Arrow's alternative and illuminating approach of externalities" that also distinguishes them from increasing returns (ibid., 17).

Finally, to sum up Arrow's position, market failures only refer to missing markets. And missing markets refer to externalities but also include other missing markets, such as the absence of future markets or markets for risk hedging. "The problem of externality is thus a special case of a more general phenomenon, the failure of markets to exist. Not all examples of market failure can fruitfully be described as externalities.” (Arrow 1969, 148) But unfortunately, Arrow never specifies the nature of the difference between externalities and other missing markets.

\footnotetext{
${ }^{21}$ Since convexity is not required for the first theorem but only for the second one.

${ }^{22}$ In a footnote they stress that increasing returns give rise to a number of problems, among which is "the danger of breakdown of the second-order conditions" (that is the non-convexity problems) but that "none of these is, however, an externalities problem in the conventional sense and each has given rise to a distinct body of literature" (ibid., 16).
} 


\section{III.2 Arrow's illustration and formalisation}

To illustrate this association of externality with missing markets, Arrow establishes the conditions of Pareto optimality for a general competitive equilibrium with externalities. ${ }^{23} \mathrm{He}$ provides an example in which the consumption of an individual $i$ impacts the satisfaction of all the other individuals and can therefore be considered a joint production. More precisely, "what we ordinarily call $i$ 's consumption is regarded as the production of joint outputs, one for each individual whose utility is affected by individual i's consumption" (Arrow 1969, 146). In other words, agent $i$ 's consumption, $i=1, \ldots, n$, actually produces a multitude of distinct externalities and, on the other side, his own utility now also depends on the $n-1$ other agents' consumption:

$$
u_{i}=u_{i}\left(\mathrm{q}_{11}, \ldots, q_{i k}, \ldots, q_{n m}\right), \quad i=1, \ldots, n ; \quad k=1, \ldots, m,
$$

where $q_{i k}$ is the quantity of good $k$ consumed by agent $i$.

From an analytical point of view, externalities appear here since individual $i$ can only choose or control the quantities $q_{i k}, k=1, \ldots, m$ that he consumes but not the quantities $q_{j k}, j \neq i$, $k=1, . ., m$, consumed by all the others, although these quantities impact his utility. So externality takes the mathematical form of a 'direct' individual interaction, i.e., a nonindependence of the utility functions.

The solution is then to show that "by suitable and indeed not unnatural reinterpretation of the commodity space, externalities can be regarded as ordinary commodities, and all the formal theory of competitive equilibrium is valid, including optimality" (Arrow 1969, 146). Since externality is characterised as a "missing market", the Pareto optimality requires the creation of artificial markets or "artificial goods" (Laffont 1977), i.e. the broadening of the complete system of markets to all externalities and the creation of new prices. The new commodities are characterised by both agents - the producer $i$ and the recipient $j-$ and by a price $p_{i j k}$ set by the auctioneer. In other words, externalities are now personalised:

$$
u_{i}=u_{i}\left(q_{i 11}, \ldots, q_{i j k}, \ldots, q_{i n m}\right), \quad i=1, \ldots, n,
$$

where $q_{i j k}$ is the quantity of goods $k$ consumed by $j$ and impacting $i$.

It is possible to show that such a system of equilibrium and personalised prices exists and is Pareto optimal. ${ }^{24}$ "The competitive equilibrium of an economy with a broadened price

\footnotetext{
${ }^{23}$ Its existence had already been proven by McKenzie (1955).

${ }^{24}$ Internalisation by the creation of competitive markets raises several well-known problems: first, the relevance of the price-taking assumption with only two agents per market as underlined by Arrow (1969) himself or later by Laffont (1977) since the price-taking assumption is usually justified by 'atomistic competition'.As stressed by
} 
system will be Pareto optimal since no externality remains" (Laffont 1977, 264). Since the sub-optimality disappears, so do externalities: the sub-optimality of externality is nearly constitutive of its definition. As underlined by Papandreou, the usual expression of "market for externality' is wrong in the general equilibrium framework: "Here, 'externality markets' is an oxymoron. It is either markets or externality, but not both" (Papandreou 2003, 285).

This approach of externalities seen as missing markets and its internalisation by competitive markets calls for a few remarks. First, it leaves aside the issue of the origin of these externalities since, as is well known, general equilibrium theory takes the number of markets and more generally institutions as given. As pointed out by Laffont (1988), "the general equilibrium model of 'Arrow-Debreu' does not seek to explain variables such as the agents' size or the number of markets, as well as he does not explain agents' preferences" and "we will remain captive of this model" (Laffont 1988, 14). To such an extent that agents could also be called 'market takers': "Precedent for behaving passively with respect to one's environment is well established in the Walrasian tradition of price taking, so market-taking would seem to be part of the same mold" (Makowski and Ostroy 2001, 490). So we are left with the absence of markets or prices for externalities without explanation, and the question of the origin of the missing markets - lack of property rights, transaction costs - is beyond the scope of this framework. ${ }^{25}$

Next, even in such a unified and rigorous framework, the concept of externality regarded as a missing market is not so straightforward. This is the issue on which I will now focus. More precisely, the concept does not clearly specify two features which are usually associated with externalities as harmful or side effects: first, whether or not an externality is an exogenous or uncontrollable effect for the recipient and, second, whether or not it is an unintended effect for the producer of externalities. I argue that both ambiguities raise the

\footnotetext{
Arrow $(1969,146)$, "each commodity $(i, j, k)$ has precisely one buyer and one seller $[\ldots]$ We are in the realm of imperfectly competitive equilibrium". The second problem is the non-convexity problem raised by Starrett (1972): the creation of a market for a detrimental externality can undermine the production set convexity and thus the existence of equilibrium. For example, an impacted producer facing a positive price for an externality can choose to stop his production and can ask an infinite demand for externality. The problem of convexity with Arrovian markets has been intensively discussed but is not important here. See also Laffont (1976), Starrett and Zeckhauser (1974) and more recently, Boyd and Conley (1997) or Papandreou (2003), for example.

${ }^{25}$ As soon as one seeks to explain externalities, the notion of transaction costs - as exclusion costs, for example - becomes essential and thus undermines the previous necessity of internalisation. In order to explain why markets are missing, Arrow introduces such transaction costs at the end of his (1969) paper. Then he changes his previous conception of failure which becomes relative (see Papandreou 1994 or Berta and Bertrand 2014). Nevertheless, he did not mention the transaction costs issue in his presentation of externalities a few years later (Arrow and Hahn 1971). The introduction of transaction costs would lead to abandonning the Arrow-Debreu framework, on which the present paper focuses. This is why, as already underlined, the Coasean tradition and the property rights school are beyond the scope of our study.
} 
issue, although in a different manner, of the frontier between externality and the broader notion of individual interdependence.

\section{The uncontrollable or exogenous feature of externality}

Some authors (Heller and Starrett 1976, Laffont 1988) regard barter as an externality, considering that it involves a direct negotiation between agents and thus produces a kind of direct interdependence of individual choices. Their association between externality and barter is logically based on the utility-interdependence that both formally produce. Nevertheless, this association challenges the definition of externality as a missing market - since barter remains a market, although it is not a competitive one. As a consequence, it challenges the uncontrollable dimension of externality that follows from Arrow's definition. More broadly, I want to show that this assimilation questions the distinction between externality and simple economic interdependence. This section first underlines the uncontrollable dimension of externality, implied by the Arrovian definition of externality as a missing market and its formalisation as a utility-interdependence (IV.1). It then discusses the argument put forward by Heller and Starrett (1976) and Laffont (1988) to regard barter as an externality (IV.2).

\section{IV.1 The externality-taking assumption}

The uncontrollable or exogenous character of an externality for the recipient is not explicit in the definition of externality as a missing market or an unpriced effect, even if it has been emphasised by several authors as such. ${ }^{26}$ This uncontrollable or exogenous character is driven by the model: this is clarified when we look at the basic formalism used to represent externality.

In the institutional framework of perfect competition, each individual decision is, by definition, based on parametric prices: each individual chooses his optimal quantities - those that maximise his profit or utility - at the given prices. All interactions are market interactions, in the sense that they go through the parametric prices set by the auctioneer.

\footnotetext{
${ }^{26}$ Buchanan and Stublebbine (1962) are the first to explicitly refer to the lack of control in their definition: externality is formally a direct interdependence of the utility functions. An agent's utility, then, depends not only on his own 'activity' vector but also on another agent's activities "which by definition are under the control of [this] second individual" $(1962,372)$. Years later it is also underlined by Meade (1973), who evokes "not fully consenting parties" (cited by Cornes and Sandler 1986, 39), and Baumol and Oates (1975) who evoke "values chosen by others".
} 
Consequently, as is well known, there is no direct individual interaction: each individual only faces the auctioneer and adjusts his choices to the parametric prices. The Walrasian competitive framework avoids any strategic behaviour regarding not only prices - according to the price-taking assumption - but also the other agents. As a consequence, there is no dependence between individual objective functions: each agent's utility function only depends on his own choices at the given prices - from a mathematical viewpoint, all the arguments of his function are controlled, chosen by the agent given the parametric prices.

Externality seen as a missing market is an unpriced effect that impacts the utility or production function of an individual. In other words, it means that, from a mathematical point of view again, the externality produced by an agent directly enters the objective function of another agent. This unpriced - or direct - interdependence between utility or production functions is a violation of the previous non-dependence of the objective functions ensured by the competitive framework. As stressed by Laffont in the New Palgrave Dictionary, "the formalization of externality is achieved in microeconomics by making consumption sets, utility functions and production sets (or functions) affected by externalities functionally dependent on the activities of the other agents" (Laffont 1987, 263). It does not mean that when the objective functions are non-dependent (or not "functionally dependent", according to Laffont's previous definition), there is no individual interdependence. The non-dependence of objective functions is opposed to unpriced or 'direct' interdependence but not to individual interdependence. As already stressed, a priced effects (or an internalized externalities) are individual interdependences but are not externalities any more, even if the effect (the phenomenon) remains.

As a consequence, the externality is an argument of the recipient's production or utility function but it is not a controlled variable for him. Since the externality has no price, the agent cannot choose its amount. ${ }^{27}$ This argument of the function is then exogenous for the recipient. As clearly underlined by Arrow and Hahn (1971):

\footnotetext{
${ }^{27}$ However, as underlined by Papandreou (1994), the issue of control slips away if we consider, like Coase (1960), that the harmed agents have ways to evade the externality, for example by moving away from the producer of the nuisance or by protecting themselves. "It often looks as if the distinction between external and internal has to do with the degree of control an agent has over a decision, but it is never quite clear how this distinction can be made, short of a general interdependence vis-à-vis total independence" (Papandreou 1994, 47). Actually, in the Arrow-Debreu model, commodities are spatially specified (see, for example, Debreu 1959). This very strict definition of the commodity space ensures that the individuals' choices are only based on the prices and that the quantities will not depend on the location of commodities. Obviously, this strong assumption stops the Arrow-Debreu model from taking moves by agents into account. I will return to the definition of the commodity space later.
} 
"In accordance with the atomistic connotations of the concept of competitive equilibrium, each household and firm is assumed to take externalities as parametrically given." (Arrow and Hahn 1971, 133, our emphasis)

Formally, impacted agents take externalities as given in the same way that they take prices as given, when they optimise their function. This is why I suggest that they could be said to be externality takers. The term 'external' refers to exteriority not only from the price system but also implicitly from the recipient's optimisation program. This exogenous feature of externality is - even implicitly - part of the definition and is clearly reflected by the way externalities are formalised by Arrow (1969) and in the Arrow-Debreu model and, more extensively, in microeconomics. ${ }^{28}$

Arrow's (1969) previous illustration of consumption externality can be generalised by making each agent's utility function depending not only on his own activity vector but also on the activity vectors of all the others agents, regarded as externalities. This generalisation is used a few years later by Arrow and Hahn (1971). More generally, agent $i$ 's utility function and his consumption set are assumed to depend on his entire 'environment'. Hence, if $x_{i}$ is the activity vector of agent $i$, and $x_{-i}=\left(x_{1}, . ., x_{i-1}, x_{i}+1, \ldots, x_{n}\right)$ is his environment - that is, the other agents' activities - then:

$$
u_{i}=u_{i}\left(x_{i}, x_{-i}\right) \quad i=1, \ldots, n,
$$

Then agent $i$ maximises his utility choosing only $x_{i}$ and taking his environment - all the externalities $x_{-i}$ produced by the others - as given, in the same way that he takes prices as given. These exogenous arguments can refer, for example, to neighbourhood effects, harmful effects or Veblen effects on the consumption side or on the production side to Meade's unpaid factors, to pollutions or to inventions. ${ }^{29}$

\section{IV.2 The ambiguity of barter as an externality}

In the same tradition as Arrow (1969), Heller and Starrett (1976) raise the issue of the definition of externalities. They also belong to the general equilibrium approach and both were Arrow's students at Harvard University (and later edited the "Essays in honor of Kenneth J. Arrow" (Heller, Starr and Starrett 1986)). In 1976, Starrett had already published

\footnotetext{
${ }^{28}$ In Arrow's formalisation (see its presentation above, in III.2), agent $i$ chooses his own consumptions $q_{i k}$ indexed by $i$, while he has no control over the consumptions of other agents $q_{j k}, j \neq i$. This is also the traditional way externalities were formalised e.g., in Meade (1952) and in Buchanan and Stubblebine (1962).

29 According to Scitovsky $(1954,144)$, "inventions are part of 'producer's direct (i.e. nonmarket) influence on personal satisfaction" since inventions "facilitate production and become available without charge".
} 
his famous contribution on the fundamental non-convexities that some negative externalities can imply on the production side (Starrett 1972). ${ }^{30}$

Heller and Starrett (1976) follow Arrow's approach and also try "to explore the nature of externality from a rigorous analytic viewpoint" $(1976,9)$. They consider that externality is related to the perfect competition framework: "an externality is frequently defined to occur whenever a decision variable of an economic agent enters into the utility function (or production function) of some other agent. We shall argue first that it is not a very useful definition, at least until the institutional framework is given" (ibid., 9). Indeed, with such a definition, a barter economy is an extreme case of widespread externalities since "if I am trading with you, my welfare is going to depend on how much you're willing to give up in exchange" (ibid., 10). In other words, I do not have entire control over the quantity I consume since it now depends directly on what you agree to give me - my welfare or my utility function depends directly on your choices. In this sense, barter creates a kind of dependence of the utility functions, a direct interaction between the two agents. That is why, according to Heller and Starrett, externality must only encompass "situations in which interdependencies exist even in the framework of the market system". Thus, "only the introduction of a competitive market eliminates externalities by isolating individuals through price taking" (ibid., 10).

As stressed above (IV.1), the perfect competitive framework ensures that there is no direct individual interaction since each agent makes his choices regarding the parametric prices, independently of the other agents' choices. Perfect competition, through the pricetaking assumption, is considered the way to 'isolate' agents - a way which is ensured by the presence of the auctioneer. So according to Heller and Starrett, two polar situations emerge: "at one extreme, is the barter situation where everything is an 'externality'. At the other extreme is the situation discussed by Arrow" (ibid., 10) where no externality remains.

Laffont also clearly follows Arrow (1969) and the general equilibrium approach. He was Arrow's student at Harvard University during his $\mathrm{PhD}$ at the beginning of the 1970s and started to work on this topic at that time (see Laffont and 1972, Laffont 1975 and Laffont

\footnotetext{
30 This contribution clearly relies on Arrow's (1969) definition but stresses an important limit to the internalisation by Arrovian markets (see footnote 23 above). When Starrett shows that negative externalities can produce non-convexities (e.g., when a producer chooses to stop producing and asks an infinite quantity of externality at its positive price), there is an apparent contradiction with Arrow's definition that excludes nonconvexities issues (such as increasing returns) from the field of externalities. In my opinion, the non-convexity of the production set is only a potential consequence (and not a systematic one) of some important negative externalities, but it is not a cause of externalities. Arrow clearly identifies market failures to all that undermine the first theorem of welfare economics but convexity is not required for the first theorem.
} 
1976). A few years later, in a book devoted to public economics (Laffont 1988), ${ }^{31}$ he has nearly the same interpretation of barter as Heller and Starrett, although he does not refer to their contribution. He gives a longer explanation: "In a barter economy, that is without markets, every exchange can be broken down into two externalities. The quantity $q_{l j}$ of good $l$ that agent $j$ accepts to exchange for a quantity $q_{k i}$ of good $k$ with agent $i$ creates an externality on agent $i$. Agent $i$ 's utility depends on his action $q_{k i}$ but also on agent $j$ 's action $q_{1 j}$. On the contrary, one could create a market for each agent activity in relation with all the others. Then, there is no more external effect" (Laffont 1988, 14). Given the reciprocal dimension of barter, each exchange generates two externalities: one from agent $i$ on agent $j$, and the reverse. Again, what is at stake is not the individual interdependence per se, since every market transaction is interdependence, but the fact that the interdependence is direct: every individual choice depends directly on the other agents' choices, and the utility functions of the agents are not independent any more. This is why Laffont also stresses that externalities are dependent on existing institutions (number of markets but also number of firms). ${ }^{32}$

The assimilation of a barter economy with a situation of widespread externalities raises several problems. First, it implicitly denies any relevance to Coase's (1960) solution of bargaining. While the Coase theorem has different interpretations, Coase's own solution is within a bargaining framework without price taking, i.e. in an Edgeworthian framework of bilateral negotiation. ${ }^{33}$ There is an inconsistency in regarding bargaining or barter - exchanges without price taking - both as an externality and an internalisation mode.

Secondly, whether it concerns a simple bilateral exchange or an exchange involving an infinite number of agents, Edgeworthian equilibria - the 'core' of the economy - are Pareto optimal, under the implicit assumption that agents will reach the contract curve, i.e. that there is not a mutually beneficial exchange any more. In other words, there is no relation between barter or bargaining and sub-optimality. If barter is regarded as an externality, one could have both an optimal situation and a persistent externality and the previous sub-optimality of externality would be undermined. As already stressed, externality is a kind of market failure and its sub-optimality is nearly part of its definition: externality disappears as Pareto optimality is reached via its internalisation.

\footnotetext{
${ }^{31}$ Book that has been first published in French in 1982.

${ }^{32}$ It is obvious that, if a firm that pollutes another one buys the latter, the externality is internalized, becomes an internal problem and disappears (even if the pollution may remain).

${ }^{33}$ The Coase theorem may also be interpreted in terms of perfect competition. But the interpretation that Coase himself - and also Stigler (1966) or Calabresi (1968) - gives to the Coase theorem is in terms of bargaining. For more details, see Bertrand (2006).
} 
Finally, this assimilation of barter and externality raises the question - and this is the issue on which I want to focus - of the uncontrollable nature of externality and, beyond that, of the frontier between externality and simple economic interdependence. As stressed above, externalities are regarded as "parametrically given" by the recipient and this exogenous character is embedded in the mathematical structure: the amount of externality is not chosen by the recipient who can be considered an externality taker. If we return to the above illustration of barter between good $l$ and good $k$, Laffont (1988) considers this barter an externality since agent $i$ 's utility depends on his own choice $q_{i k}$ of good $k$ but also on the quantity $q_{j l}$ of good $l$ that agent $j$ is willing to exchange. But to have agent $i$ treating externality as "parametrically given" and behaving as an externality taker agent, the quantity $q_{j l}$ must be exogenous for him. And in barter, the exchanged quantities result from a voluntary exchange or negotiation. Agent $i$ is always able to choose the quantity, even indirectly, since it also depends on the quantity $q_{i k}$ he is willing to exchange. For example, he can always refuse to exchange and choose to consume $q_{j l}=0$. So the quantity $q_{j l}$ is not as exogenous or uncontrollable as pollution or neighbourhood effects, for example. In other words, while in a barter, "my welfare depends on what you're willing to give up in exchange" (Heller and Starret 1976, 10), you do not choose what I am going to consume. Finally, in a direct negotiation without price taking, I cannot choose my optimal quantities independently, as would be the case in a competitive framework, but I do not lose complete control of the quantity I consume. ${ }^{34}$

What is at stake in this association of barter with externality is the definition of market. In Laffont's quotation above, market is associated with competitive market and externality with barter. But barter is a market, even though not a competitive one, and both involve voluntary exchanges and controllable decisions. So there is an inconsistency in associating an externality, which is formally an uncontrolled argument of the utility function, with barter, which involves a chosen, voluntary and thus controllable decision. Furthermore, barter actually creates an economic interdependence between agents, as occurs with every exchange, but this is a special kind of market interdependence that is not unpriced. So considering barter an externality challenges both the definition of externality as a missing market and the previous distinction between externality and simple economic interdependence. This is why Heller and Starrett (1976) argue that the definition of externality

\footnotetext{
${ }^{34}$ Furthermore, even if agents were not price takers, barter results in an implicit relative price or exchange rate.
} 
as an interdependence of utility or production functions "is not a very useful definition, at least until the institutional framework is given" (ibid., 9), namely the competitive framework.

\section{The unintended feature of externality}

This frontier between externality and interdependence is also challenged, in a different manner, by another dimension of externality - its unintended feature - which is sometimes associated with externality ${ }^{35}$ but not specified in its definition as a missing market. What is interesting here is that the mathematical form of externality, and the way it is formalised, does not specify whether externality is a deliberate or unintended effect. Several authors - Mishan (1965, 1969) and Baumol and Oates (1975) - claim that this unintended feature should be part of the definition, in order to circumscribe externalities to specific kinds of phenomena.

The emergence of this phenomenological approach of externalities (Papandreou 1994) has several explanations. First, it follows from the loose relationship between the ArrowDebreu formalisation of externality as utility-interdependences and its economic interpretations. This formalisation may have wide interpretations and encompass every unpriced individual interaction (V.1). So the phenomenological approach tries to circumscribe these interpretations, especially to exclude deliberate effects, in order to avoid the dilution of externality in broad interdependence (V.2). This approach also follows from the rise of environmental economics in the 1960s and 1970s and from the increasing focus on environmental issues (see Papandreou 1994, Medema 2014A). Mishan, Baumol and Oates limit the concept of externality to phenomena that fit in with environmental externalities that are obviously incidental (V.3). Finally, this approach raises important issues because of the normative content of externality: as stressed by Mishan, setting the scope of externality also amounts to drawing the field of application of the concept, i.e. of internalisation. Moreover excluding deliberate effects or social feelings is for Mishan a way to limit externalities to economic activities (V.4).

\footnotetext{
${ }^{35}$ The involuntary feature of externality is implicitly specified by Meade (1952) who is interested in situations where a producer "does not take into account" the impact of his activities on others. Heller and Starrett also specify that "externalities arise whenever the value of an objective function [...] depends upon the unintended or incidental by-products of some activity of others" (Heller and Starrett 1976, 1), but they then refer to the usually accepted definition and not to their own definition.
} 


\title{
V.1 Externality versus interdependent utilities
}

The canonical formalisation of externalities as utility-interdependences may have various meanings, since the axiomatic form of the general equilibrium theory relies on a formalism that allows very broad interpretations. This plasticity is often seen as one of its most powerful features.

\begin{abstract}
"One cause for the persistence of neoclassical theory in the face of its long line of critics is precisely that for some reason of mathematical structure, the neoclassical theory is highly manipulable and flexible." (Arrow 1974, 2)
\end{abstract}

In the same line of reasoning, Debreu has often claimed that the mathematical structure of the theory can be separated from its economic interpretations. According to him and Bourbakist tradition he follows, this dichotomy is the result of the axiomatisation achieved in the Arrow-Debreu model and gives freedom in presenting its economic meaning. ${ }^{36}$ Indeed, it is usually by reinterpretations of the commodity space that the economic meaning is enlarged. For example, commodities have been not only physically and spatially specified but also temporally specified, in order to introduce time (and futures markets). Arrow (1953) has provided a broader interpretation - commodities are now defined by the state of the world in which they are available - in order to introduce a kind of uncertainty in the analytical framework (see also Debreu 1959, 1977, Hildenbrand 1983). ${ }^{37}$ And it is also by a reinterpretation of the commodity space that the complete system of markets has been broadened to cover externalities. ${ }^{38}$

The basic formalism associated with externality as an interdependence of utility functions (or production functions) allows the broadening of the concept to all unpriced individual interactions by simple reinterpretations of the commodity space and the utility function: these interdependences of utility may refer to neighbourhood effects, pollution, Veblen effects and, more broadly, to social feelings like envy, etc. Furthermore, as stressed by

\footnotetext{
${ }^{36}$ Debreu's epistemological position, and the freedom in interpretations that he often claims, come from the influence of the French mathematical school of 'Nicolas Bourbaki' that deeply influenced him when he was studying mathematics in Paris at the Ecole Normale Supérieure. See Debreu (1977), for example. For a discussion of his epistemological position, see Berta (2000) and Mirowski and Weintraub (1994).

${ }^{37}$ See also Papandreou (2003) for an original and new interpretation of the commodity space. He stresses that there is a lack of isomorphism between the physical definition of the commodity space and its institutional definition. The definition of the commodity space could be enlarged to specify whether or not commodities are controlled, e.g., whether or not commodities have prices or property rights.

38 As already stressed above (section III): "by suitable and indeed not unnatural reinterpretation of the commodity space, externalities can be regarded as ordinary commodities, and all the formal theory of competitive equilibrium is valid, including optimality" (Arrow 1969, 146).
} 
Stigler $(1966,111)$, "there can be no doubt of the existence of these external effects of an individual's behaviour. In fact, in strictest logic there are very few actions whose entire consequences accrue to the actor. If I educate my children well, the community (it is hoped) will benefit by reduced crime, more enlightened citizenship, and so forth. If I grow an attractive lawn, my neighbours are pleased; if Smith dresses shabbily, the other members of the United States Senate become annoyed".

\section{V.2 Externality as a specific phenomenon}

Several authors have tried to limit the extension of the concept of externality in order to avoid its dilution in the larger notion of individual interdependence. Mishan $(1965,1969$, 1971) is emblematic of this desire to limit the kind of utility interdependences that externality should encompass.

\footnotetext{
"The term is evocative of interdependences of various kinds all carrying the implication that the perfectly competitive solution does not suffice. The concept is far from being unambiguous in consequence of misapplications or, on another interpretation, of arbitrary extensions of its original meaning. If the cutting edge of this powerful analytic tool is to be restored, an attempt must be made to chip away much of the accumulating accretions of meaning that have attached themselves to this term over time.” (Mishan 1965, 4-5)
}

Mishan claims that externalities correspond to unintended phenomena and he considers this feature to be the very essence of externality. And he stresses that the mathematical formalisation of externality does not specify this unintended feature:

\footnotetext{
"What the notation alone does not succeed in conveying, however, is that the essential feature of the concept of an external effect is that the effect produced is not a deliberate creation but an unintended or incidental by-product of some otherwise legitimate activity." (Mishan 1971, 2, my emphasis)
}

When, for example, one formally considers an externality to be a joint production following Arrow's (1969) illustration of externality in consumption - "the notation alone" does not specify whether or not the action is voluntary. And Mishan refuses to accept that externalities encompass deliberate acts of goodwill or malice, invoking then the "popular" meaning of externalities or the "essence of [its] common conception" (Mishan 1969, 343). 
"If deliberately and with malice aforethought, I pour hydraulic acid in the pure waters of a stream used by a whiskey distillery, or if I gradually poison my motherin-law, I certainly affect the production function of the former and the consumption function of the latter. But neither activity accords with the popular notion of a spillover or external effect." (Mishan, 1969, 343) 39 $^{39}$

In the same way, Baumol and Oates (1975) stress this unintended feature of externality. Following the general equilibrium approach, they characterise externality as a direct and unpriced interaction, i.e. an agent's activity that affects other agents' utility or production function but that "does not receive (pay) in compensation for this activity" (ibid.). But they add a condition: that these externalities which enter A's utility or production function have "values [that] are chosen by others without particular attention to the effects on A's welfare" (Baumol and Oates 1975, 16).

Of course, as emphasised by Papandreou (1994, 73), asserting that actions are both "chosen by others" and "without particular attention" can seem inconsistent since making a choice induces a conscious decision. For example, if an industry voluntarily chooses a polluting input, this choice cannot be considered unintentional, and conscious and involuntary features are negatively correlated. But, this opposition is not so straightforward: it is possible to choose a level of externality consciously and "without particular attention" for its effects on others, even if these effects are well known. An industry chooses a polluting technology because it is less costly and not because it is a polluting technology per se, i.e. without particular attention to its harmful effects. ${ }^{40}$ In other words, the level of externality can be a controlled variable in the optimisation program - and thus a conscious decision - on the part of the producer of externality, without one being able to say if the latter deliberately chooses to impact others, whether positively or negatively, i.e. if it is a deliberate act of goodwill or

\footnotetext{
39 "A definition of external effects emerges that accords with the common conception but differs somewhat from other definitions in which external effects turn on (a) welfare or production effects that are wholly or partially unpriced, or (b) the dependence of a production function or a consumption function on the activities of others, or (c) the inability of the firm to control the factor. The essence of the common conception of an external effect, one that is consistent with the usage in this paper, turns on its incidental character. The effect on others' welfare, though direct $[\ldots]$ is always an unintentional product of some otherwise legitimate employment. It therefore does not cease to exist when the external economy or diseconomy is properly priced so as to insure that an optimal output is attained. And it does not necessarily exist when the production function of a firm or the consumption function of a person is altered by the activities of others." (Mishan 1969, 343)

${ }^{40}$ If I listen to music at night-time, I can choose the amount of externality while being conscious of the annoyance caused to my neighbors but it does not mean that I choose this amount 'with particular attention' to this annoyance. I choose this amount with particular attention to my own welfare.
} 
malice. What is at stake is the intention behind the choice - intention that, as already stressed by Mishan (1971, 2), "the notation alone does not succeed in conveying".

Baumol and Oates pursue without ambiguity:

"This definition [of externality] should not be misunderstood to be a simple equation of externalities with economic interdependence. When I rely on farmers for my food, no externality need to be involved, for they do not decide for me how many zucchini I will consume, nor does my consumption enter directly into their utility function. Note also that the definition rules out cases in which someone deliberately does something to affect A's welfare, a requirement Mishan has emphasized. If I purposely manoeuver my car to splatter mud on a pedestrian whom I happen to dislike, he is given no choice in the amount of mud he 'consumes', but one would not normally regard this as an externality." (Baumol and Oates 1975, 17) ${ }^{41}$

When underlining the unintended feature of externality, Mishan, Baumol and Oates all try to limit the notion to very special phenomena, and all put forward what they regard as the “original”, "popular" or "conventional" (Baumol and Oates 1975, 16) meaning of externality. This meaning fits in with environmental externalities, the study of which has become more and more important since the early 1960s.

\section{V.3 The rise of environmental externalities}

Papandreou (1994) associates the phenomenological approach with the rise of environmental issues and concerns since the early 1960s. The context is indeed important. As stressed by Medema (2014A, 2014B), the relatively sparse literature on externalities before the 1960s can be explained by the fact that economists regarded externalities, and especially externalities on the production side, like pollution - as rare and unimportant phenomena, with no real empirical relevance. The growing interest in environmental problems since the 1960s explains the rapid simultaneous development of environmental economics and externality theory. This rise renews the empirical relevance of the externality problem and contributes to closely relating externality to specific and tangible effects (see Papandreou 1994, 46). Baumol and Oates clearly adopt this phenomenological approach because they are interested in

\footnotetext{
${ }^{41}$ This definition obviously excludes simple 'priced' interdependences, as shown by the example of exchange with farmers in the quotation. They add in a note: "of course, my payment to him does affect his utility. This already brings in the distinction between pecuniary and technological externalities." (ibid., 17)
} 
environmental issues and focus on specific harmful effects, such as pollution, that cannot be regarded as deliberate acts of nuisance. The intuitive feature of externality as a side effect or accidental joint production - its unintended feature - is obviously central in the field of environmental economics. ${ }^{42}$ This can explain why, in the 1970s, this unintended feature of externality was regarded by Mishan, Baumol and Oates as a "popular" or "conventional" meaning of externality.

Papandreou (1994) also distinguishes this phenomenological approach from the general equilibrium approach and explains their differences. But it is important to stress that there is no real contradiction between the general equilibrium approach and the phenomenological approach: the latter is just a sub-set of the former, since unintended and deliberate effects take the same mathematical form, i.e. unpriced or nonmarket effects that create direct interdependences of the individual objective functions. Furthermore, this distinction is not so straightforward. Baumol and Oates adopt this phenomenological approach because of their focus on environmental issues, but they are also working within a general equilibrium framework. Mishan, on his side, also adopts this phenomenological approach because he focuses on environmental issues, but he has political reasons in addition, as shown below.

\title{
V.4 The scope of legitimate internalisation
}

Mishan's attempt to limit the definition of externality can also be explained by a different reason: by a matter of public policy. Utility interdependences can also be regarded as reflecting social feelings, such as Veblen effects, altruism, envy ${ }^{43}$ and so on. Mishan does not only reject voluntary or deliberate effects - as stressed above - but also social feelings like “ill-feeling induced by the knowledge of other people's good fortune".

\begin{abstract}
"Although the interdependent-utility case may be expressed in the same functional form as external effects on consumption, it may be expedient to exclude its classification under external effects. It is possible, of course, $[\ldots]$ to concern oneself with all those factors that may affect the welfare of the individual. Welfare
\end{abstract}

\footnotetext{
${ }^{42}$ As Stavins argues later in The New Palgrave: "the fundamental theoretical argument for government activity in the environmental realm is that pollution is an externality - an unintended consequence of market decisions which affect individuals other than the decision maker." (Stavins 2008).

${ }^{43}$ Envy can be considered a negative externality (Sussangkarn and Goldman 1983), even if economic theory gives various meanings to the feeling of envy (Kolm 1995, Pignol 2012). Mishan also evokes ostentatious consumption (Duesenberry 1949).
} 
propositions may, in principle, be tested if we agree to accept people's opinions about their welfare as evidence [...] One can well imagine that the costs of the more tangible external diseconomies, such as obstruction noise, and smoke, are readily accepted as such by a consensus. [...] If on the other hand, a man were bold enough to complain that the mere fact of others becoming better off saddened him considerably, we may have some sneaking sympathy with him. But it is hardly likely that practical measures would be contemplated which were calculated to impoverish others in the hope of restoring his spirits." (Mishan 1965, 7-8)

Moreover, he makes a distinction between "tangible" external effects, such as spillovers, and "psychic externalities" associated with interdependent utilities (Mishan 1969). Underlining again that both have the same mathematical form, he chooses to ignore the latter. In other words, he makes a distinction between, on the one hand, the definition of externality as incidental side effects and, on the other hand, its mathematical form as unpriced interdependent utilities, which largely encompasses voluntary effects and social feelings. While rejecting the latter, he implicitly draws the frontier of public intervention and internalisation. He argues that "in fact, no government has ever proposed taking account of them" $(1965,8)$ or that "they play no part in economic policy and are ignored in all costbenefit studies" $(1969,329)$. According to him, the fact that externality is an unintended byproduct of some otherwise legitimate activity "influences the economist's and public's attitude towards externalities and, consequently, also influences remedial policies" (Mishan 1965, 2). Finally, when he rejects deliberate effects or more widely psychic externalities, Mishan wants to limit externalities to economic activities, to activities that could require "economic policy". Mishan underlines the strong normative content of the concept and hence the scope of its applications. Since externality, as a cause of sub-optimality, requires its internalisation, creating a strict definition of externality amounts to establishing the scope of legitimate public intervention, and to limiting the cost-benefit analysis to economic activities.

\section{Conclusion}

The standard definition of externality as a 'missing market' is not so straightforward, even in a unified and rigorous framework such as the Arrow-Debreu model. This is due to the mathematical form of these missing markets, i.e. to their formalisation through direct interdependences between utility or production functions. 
In a competitive framework where every choice is made through the prism of parametric prices, every unpriced effect is necessarily out of the recipient's control, who then regards externality as parametrically given. This is why barter is an ambiguous case: it does create a direct interdependence between individuals' choices but cannot be considered an externality, first, because it remains a market and, second, because it would upset the difference between externality and the broader notion of economic interdependence. While all exchanges are interdependences, all interdependences are not externalities.

The definition of externality as a missing market allows a second ambiguity to persist. This is due to the basic formalism which does not specify whether or not externality is an unintended or deliberate effect, formalism which allows for wide interpretations. As social life is obviously full of 'unpriced' individual interactions, there is no limit to the application of externality. This is why Baumol and Oates as well as Mishan call upon a more traditional meaning, close to environmental effects whose importance was more and more recognized in the 1960s. They try to limit these various interpretations to unintended effects, in order to avoid the fact that externality could encompass every unpriced individual interaction.

These exogenous and unintended features of externality thus raise two important issues. Firstly, both raise, but in a different manner, the question of the dilution of externality into the broader notion of individual interdependence. Secondly, and as a consequence, this dilution raises a strong normative issue. Since externality produces a sub-optimality that calls for internalisation, its definition implicitly establishes the scope of its application. So we are left with the question raised by Arrow himself in 1969: "there is one deep problem in the interpretation of externalities which can only be signalled here. What aspects of other's behavior do we consider as affecting a utility function? [...] Do we have to extend the concept of externality to all matters that an individual cares about? Or, in the spirit of John Stuart Mill, is there a second-order value judgment which excludes some of these preferences from the formation of social policy as being illegitimate infringements of individual freedom?" (Arrow $1969,148)$

\section{Bibliography}

Arrow, K. J., 1951. An Extension of the Basic Theorems of Classical Welfare Economics, in: Jerzy Neyman, ed., Proceedings of the Second Berkeley Symposium on Mathematical Statistics and Probability. Berkeley: University of California Press, 507-532.

Arrow, K. J., 1953. The role of securities in the optimal allocation of risk bearing, Review of Economic Studies, 31, 91-96. 
Arrow, K. J., 1963. Uncertainty and the welfare economics of medical care, American Economic Review, 3 (5), 941-973.

Arrow, K. J., 1969. The organization of economic activity: Issues pertinent to the choice of market versus non market allocation, in: Congress of the United States, The Analysis and Evaluation of Public Expenditures: The PPB System, 47-64.

Arrow K. J., 1972. General economic equilibrium: purpose, analytic techniques, collective choices, Nobel memorial lecture, December.

Arrow, K. J., 1974. Limited knowledge and economic analysis, American Economic Review, 64, 1-10.

Arrow, K. J., 1979. The property rights doctrine and demand revelation under incomplete information, in: M. J. Boskin, ed., Economics of Human Welfare: Essays in Honor of Tibor Scitovsky, New York: Academic Press, 23-39.

Arrow, K. J., 1985. Collected Papers, vol. 6, Oxford: Basil Blackwell.

Arrow K. J. and Debreu, G., 1954. Existence of an equilibrium for a competitive economy, Econometrica, 22 (3), 265-290.

Arrow, K. J., and Fisher, A. C., 1974. Environmental preservation, uncertainty, and irreversibility, Quarterly Journal of Economics, 88 (2), 312-319.

Arrow, K. J. and Hahn, F. H, 1971. General Competitive Analysis, San Francisco: Holden Day.

Arrow, K. J., and Lind, R. C., 1970. Uncertainty and the evaluation of public investment decisions, American Economic Review, 60 (3), 364-378.

Arrow, K. J. and Scitovsky, T., 1969. Readings in Welfare Economics, Homewood, Illinois: Irwin.

Arrow, K., Solow R., Portney P. R., Leamer E. E., Radner R. and Schuman. H., 1993. Report of the NOAA Panel on Contingent Valuation, Federal Register, 58 (10), 4601-14.

Bator, F. M., 1957. The simple analytics of welfare maximization, American Economic Review, 47 (1), 22-59.

Bator, F. M., 1958. Anatomy of market failure, Quartely Journal of Economics, 72, 351-79.

Baumol, W. J., 1965. Welfare economics and the theory of the state, $2^{\text {nd }}$ ed., London: Bell.

Baumol, W. J. and Oates, W. E., 1975. The Theory of Environmental Policy, $2^{\text {nd }}$ ed., 1988, Cambridge: Cambridge University Press.

Berta, N., 2000. Le marché dans les modèles de Gérard Debreu, Louvain Economic Review, 66 (3), 303-308.

Berta, N., 2008. Le concept d'externalité des économies externes à l'interaction directe: quelques problèmes de définition, CES Working Papers, n²008-25, CNRS and University of Paris 1.

Berta, N. and Bertrand, E., 2014. Market internalization of externalities: What is failing?, Journal of History of Economic Thought, 36 (3), 332-357.

Bertrand, E., 2006. La thèse d'efficience du 'théorème de Coase': Quelle critique de la microéconomie?, Revue Economique, 57 (5), 983-1007.

Bliss, C., 1987. Arrow's Vision of the Economic Process in: George R. Feiwel ed., Arrow and the Ascent of Modern Economic Process, Basingstoke: Macmillan, 295-305. 
Bohm, P., 1987. External economies, in J. M. Eatwell, M. Milgate and P. Newman eds, The New Palgrave: A Dictionary of Economics, London and New York: Macmillan and Stockton.

Boyd, J. H. and Conley, J. P., 1997. Fundamental non-convexities in Arrovian markets and a Coasian solution to the problem of externalities, Journal of Economic Theory, 72, 388407.

Buchanan, J. M. and Stubblebine, W. C., 1962. Externality, Economica, 29, 371-84.

Calabresi, G., 1968. Transaction costs, resource allocation and liability rules - A comment, Journal of Law and Economics, 11 (1), 67-73.

Coase, R. H., 1960. The problem of social cost, Journal of Law Economics, 3, 1-44.

Cornes, R. and Sandler, T., 1986. The Theory of Externalities, Public Goods and Club Goods, $2^{\text {nd }}$ ed., Cambridge: Cambridge University Press.

Debreu, G., 1959. The Theory of Value: An axiomatic analysis of economic equilibrium, New Haven and London: Yale University Press.

Duesenberry, J., 1949. Income, Saving and the Theory of Consumer Behavior, Cambridge, Massachusetts: Harvard University Press.

Heller, W. P., Starr R., M. and Starrett D. A., 1986. Essays in Honor of Kenneth J. Arrow, 3 vol., Cambridge: Cambridge University Press.

Heller, W. P. and Starrett, D. A., 1976. On the Nature of Externalities, in: Theory and Measurement of Economic Externalities, New York: Academic Press.

Hildenbrand, W., 1983. Mathematical economics: Twenty papers of Gérard Debreu, Cambridge: Cambridge University Press.

Kornai, J., 1979. The oeuvre of Kenneth J. Arrow, Acta Oeconomica, 23 (1-2), 193-203.

Laffont, J.-J., 1975. Note historique sur les effets externes, L'Actualité économique, 51 (3), 420-433, in : Laffont 1977, 13-25.

Laffont, J.-J., 1976. Decentralization with externalities, European Economic Review, 7, 359375, in: Laffont 1977, 55-72.

Laffont, J.-J., 1977. Effets externes et théorie économique, Monographie du séminaire d'économétrie, $n^{\circ} 13$, Paris: CNRS.

Laffont, J.-J. and G. Laroque, 1972. Effets externes et théorie de l'équilibre général, Cahiers du séminaire d'économétrie, CNRS, 14, in: Laffont 1977, 27-53.

Laffont, J.-J., 1987. Externalities, in: J. M. Eatwell, M. Milgate and P. Newman, eds, The New Palgrave: A Dictionary of Economics, London and New York: Macmillan and Stockton.

Laffont, J.-J., 1988. Fundamentals of Public Economics. Cambridge: MIT Press, reprint and translated in: J. P. Bonin and H. Bonin, Cours de théorie microéconomique, vol. 1: Fondements de l'Economie Publique, Paris: Economica, 1982.

Lagueux, M., 2010. The Residual character of externalities, European Journal of the History of Economic Thought, 17 (4), 957-73.

Marciano, A., 2013. Why market failures are not a problem: James Buchanan on market imperfections, voluntary cooperation, and externalities, History of Political Economy, 45 (2), 223-254.

Makowski, L. and Ostroy, M., 2001. Perfect competition and the creativity of the market, Journal of Economic Literature, 39, 479-535. 
Marshall, A., 1890. Principles of Economics, $8^{\text {th }}$ ed, London: Macmillan and Co., 1920.

McKenzie, L., 1955. Competitive equilibrium with dependant consumers' preferences" in: H.A. Antosiewicz, ed., Proceedings of the Second Symposium in Linear Programming, Washington D.C, National Bureau of Standards and Directorate of Management Analysis.

Meade, J. E., 1952. External economies and diseconomies in a competitive situation, Economic Journal, 62, 54-67.

Medema, S. G., 2011. HES Presidential Address: The Coase theorem. Lessons for the study of the history of economic thought, Journal of the History of Economic Thought, 33 (1): 118.

Medema, S. G., 2014A. The curious treatment of the Coase theorem in the environmental economics literature, 1960-1979, Review of Environmental Economics and Policy, 8 (1), $39-57$.

Medema, S. G., 2014B. Exceptional and unimportant? Externalities in economic analysis, 1940-1959, Working Paper, March.

Mirowski, P. and Weintraub, E. R., 1994. The pure and the applied: Bourbakism comes to mathematical economics, Science in Context, 7 (2), 245-272.

Mishan, E. J., 1965. Reflections on recent developments in the concept of external effects, Canadian Journal of Economics Political Science, 3 (1), 3-34.

Mishan, E. J., 1969. The relationship between joint products, collective goods and external effects, Journal of Political Economy, 77, 329-48.

Mishan, E. J., 1971. The postwar literature on externalities, Journal of Economic Literature, 9, 1-28.

Newbery, D. M., 1990. Missing markets: Consequences and remedies, in: F. Hahn, ed., The Economics of Missing Markets, Information and Games, Oxford: Clarendon Press.

Papandreou, A., 1994. Externality and Institutions, New-York: Oxford University Press.

Papandreou, A., 2003. Externality, convexity and institutions, Economics and Philosophy, 19, 281-309.

Pignol, C., 2012. Rousseau's notion of envy: A comparison with modern economic theory, European Journal of History of Economic Thought, 19, 3.

Samuelson, P. A., 1947. Foundations of Economic Analysis, Cambridge, Massachusetts: Harvard University Press, 1958.

Samuelson, P. A., 1954, The pure theory of public expenditure, Review of Economics and Statistics, 36 (4), 387-389.

Samuelson, P. A., 1955. Diagrammatic Exposition of a Theory of Public Expenditure, Review of Economics and Statistics, 37 (4), 350-356.

Samuelson, P. A., 1958. Aspects of public expenditure theories, Review of Economics and Statistics, 40 (4), 332-338.

Scitovsky, T., 1954. Two concepts of external economies, Journal of Political Economy, 62, $70-82$.

Starrett, D. A., 1972. Fundamental non convexities in the theory of externality, Journal of Economic Theory, 4, 180-99.

Starrett, D. A. and Zeckhauser R., 1974. Treating External Diseconomies - Markets or Taxes?, in: J.W. Pratt ed., Statistical and Mathematical Aspects of Pollution Problems, New York: Dekker, 66-84. 
Stavins, R. N., 2008. Environmental Economics, in: S. N. Durlauf and L. E. Blume, eds, The New Palgrave: Dictionary of Economics, $2^{\text {nd }}$ ed, Palgrave MacMillan.

Stigler, G. 1966. The Theory of Prices, $3^{\text {rd }}$ ed., New York: MacMillan.

Sussangkarn, C. and Goldman, S. M., 1983. Dealing with envy, Journal of Public Economics, $22,103-12$.

Viner, J., 1931. Cost curves and supply curves, Zeitschrift für Natinalökonomie, 3, 23-46, reprint in: Stigler, G. and Boulding, K., eds, Reading in price theory, American Economic Association Readings. Chicago: Irwin, 198-232. 